\title{
The Pattern of Knockdown Resistance Mutations Correlated to the Annual Average Temperature in Field Populations of Aedes Albopictus (Diptera: Culicidae) in China
}

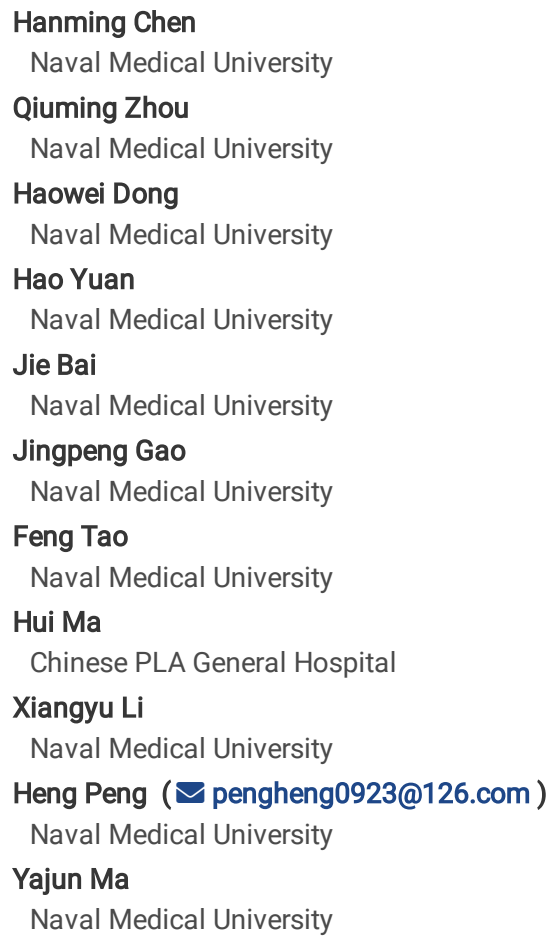




\section{Abstract}

\section{Background:}

Aedes albopictus is the main vector of dengue fever in China, distributed from north to south in China. Insecticides are an important method to control the mosquitoes, especially in the outbreak of dengue fever, but insecticide resistance raises the risk of failure to control vector-borne diseases. Knockdown resistance $(k d r)$ caused by point mutations in the VGSC gene is a key mechanism that confers resistance to pyrethroids. To explore the characteristics and possible evolution trend of $k d r$ mutation in Ae. albopictus, we analyzed the $k d r$ mutations of field populations in China in this study.

\section{Methods:}

A total of 1549 Ae. albopictus were collected from 18 sites in China from 2017 to 2019, as well as 50 individuals from three sites in the 1990 s. A fragment of approximately $350 \mathrm{bp}$ from part of S6 segment in the VGSC gene domain III was amplified and sequenced. The haplotypes of VGSC gene were recorded and the parsimony network was constructed using TCS 1.21. The data of annual average temperatures (AAT) of collection sites was acquired from national database. The correlation between AAT of the collection site and the kdr mutation rate was analyzed by Pearson Correlation using SPSS 21.0 .

\section{Results:}

The overall frequency of mutant allele F1534 is $45.62 \%$. Nine mutant alleles were detected at codon 1534 in fifteen field populations, namely TCC/TCG (S) (38.86\%), TTG/CTG/CTC/TTA (L) (3.71\%), TGC (C) (2.68\%), CGC (R) (0.27\%) and TGG (W) (0.10\%). Only one mutant allele ACC (T) was found at codon 1532 with frequency of $6.39 \%$ in ten field populations. Moreover, multiple mutations at I1532 and F1534 in a sample appeared in five populations. The 1534 mutation rate was significantly positive related to AAT (Coefficient $=0.624, p=0.0056$ ), while the 1532 mutation rate was significantly negative related to AAT (Coefficient=-0.645, $\mathrm{p}=0.0038$ ). Thirteen haplotypes were inferred, in which six mutant haplotypes were formed by one step, and the other six haplotypes were formed by one more mutations. In the samples from 1990s, no mutant allele was detected at codon 1532 of VGSC gene. However, F1534S/TCC was found in HNHK94 with an unexpected frequency of $100 \%$.

\section{Conclusions}

Kdr mutations are widespread in the field populations of Ae. albopictus in China. Two novel mutant alleles F1534W/TGG and F1534R/CGC were the detected. The 1534 kdr mutation appeared in the population of Ae. albopictus no later than 1990s. F1534 mutation rate is positive correlated to AAT, while I1532 mutation rate is negative correlated to AAT. Insecticide using should be carefully managed to slow down the spread of high-resistance Ae. albopictus populations.

\section{Background}

Dengue fever is one of the most widespread mosquito-borne diseases around the world. It was estimated that there are 390 million dengue virus infections worldwide each year (1). Dengue fever has also been an important public health emergency in China. In 2019, 22599 dengue fever cases were reported in China, and the distribution area reached an unprecedented level $(2,3)$. Due to the scarcity of therapeutic drug and effective vaccine, the vector controlling is still the main measure to prevent dengue fever(4).

Aedes aegypti and Ae. albopictus are the main vectors of dengue fever (5). Although Ae. aegypti is more susceptible to dengue virus, Ae. albopictus is considered the main vector of dengue fever in China due to its wide distribution range (6). Ae. albopictus is distributed from Liaoning Province in the north to Hainan Province in the south in China, covering tropical, subtropical and temperate climate (6). Insecticide is an essential method to control the Ae. albopictus vector, especially during outbreaks of mosquito-borne diseases.

With the advantages of high efficiency and low toxicity, pyrethroid insecticides have been widely used to control mosquito in China since 1980s (7). Although integrated control are emphasized in the general Ae. albopictus control, pyrethroid insecticides were sprayed heavily during the outbreak of dengue fever to control the epidemic quickly $(8,9)$. Long-term and mass application of insecticides has led to a serious problem -- insecticide resistance. High level and multiple pyrethroid insecticides resistance have been observed in many Ae. albopictus field populations in China (10-12).

The target of pyrethroids is voltage-gated sodium channel (VGSC), which interferes with electronic signals in the nervous system, leading to paralysis and death, an effect known as knockdown (13). The target insensitivity was a critical mechanism of the pyrethroids resistance developing, which was caused by mutations in the VGSC, so-called knockdown resistance mutation ( $k d r$ mutation) $(14,15)$.

The $k d r$ mutation in Ae. albopictus was detected firstly in Singapore in 2009 collected samples by Kasai et al (16). After that, more types of $k d r$ mutation were reported in many Ae. albopictus field populations (17), including V1016G in Italy and Vietnam (18), F1534C in Singapore, Brazil, India, Italy, Vietnam and Greece $(16,19,20)$, F1534L in America (19), F1534S in America, Italy and Vietnam (18, 19) and I1532T in Italy (19). In China, we reported F1534S and F1534L mutant alleles firstly in Ae. albopictus from Haikou, Hainan (21, 22). Soon after, The F1534S/L/C, I1532T mutations were reported in Shanghai, Jiangsu, Yunnan, Beijing, Shandong and Guangdong (19, 23-30). V1016G and D1736Y mutations were also detected in certain populations (27, 28).

More and more $k d r$ mutations have been discovered, some of which have been confirmed to be closely related to insecticide resistance (12, 31, 32). However, how these mutations appear, accumulate and spread in field populations remain a puzzling and attractive issue. Moreover, the evolution trend of $k d r$ mutation maybe the key which would determine the strategy of pesticide application in the future. 
In this study, we collected eighteen field populations from North to South China, as well as three populations in the 1990s. The types and frequencies of $k d r$ mutations were surveyed and analysis in order to explore the characteristics and possible evolution trend of $k d r$ mutation.

\section{Methods}

\subsection{Sample collection and species identification}

Eighteen field populations of Ae. albopictus were collected from in 13 provinces (municipalities) in China from 2017 to 2019 (Fig. 1). Larvae and pupae were scooped from breeding sites and brought back to laboratory, which were reared to adults under standard conditions at $26 \pm 1{ }^{\circ} \mathrm{C}$ and $65 \pm 5 \%$ relative humidity with a photoperiod of 12-h light: 12-h dark. Adult mosquitoes were collected using sucking aspirators, BG-trap (Biogents, Germany) or light trap (Houji Dianzi, China) in outdoor environment near human. To explore the historical changes of kdrmutations in Ae. albopictus, three field populations in the 1990s were also collected, including HNHK94 (Haikou, 1994), GDGZ95 (Guangzhou, 1995) and SCCD97 (Chengdu, 1997). The collection information was summarized in Table 1. Species of Aedes adult mosquitoes were identified by morphology characteristics (33) and confirmed by molecular markers (34). 
Table 1

Sampling information of Aedes albopictus field populations in China

\begin{tabular}{|c|c|c|c|c|c|c|}
\hline \multicolumn{2}{|c|}{ Collection sites } & \multirow{2}{*}{$\begin{array}{l}\text { Code } \\
\text { BJFT }\end{array}$} & \multirow{2}{*}{$\begin{array}{l}\text { Latitude/longitude } \\
\text { coordinates }\end{array}$} & \multirow{2}{*}{$\begin{array}{l}\text { Sampling environment } \\
\text { Residential area, Urban }\end{array}$} & \multirow{2}{*}{$\begin{array}{l}\text { Date } \\
\text { July } 2018\end{array}$} & \multirow{2}{*}{$\begin{array}{l}\text { Collecting method/stages } \\
\text { Sucking tube/adult }\end{array}$} \\
\hline Beijing & Fengtai & & & & & \\
\hline \multirow[t]{4}{*}{ Guangdong } & \multirow[t]{2}{*}{ Guangzhou } & GDGZ95\& & \multirow[t]{2}{*}{$23^{\circ} 07^{\prime} \mathrm{N} / 113^{\circ} 15^{\prime} \mathrm{E}$} & \multirow{2}{*}{$\begin{array}{l}\text { Outdoor area of office building, } \\
\text { Urban }\end{array}$} & June 1995 & \multirow[t]{2}{*}{ Scooping/larvae, pupa } \\
\hline & & GDGZ & & & November 2019 & \\
\hline & Shantou & GDST & $23^{\circ} 21^{\prime} \mathrm{N} / 116^{\circ} 40^{\prime} \mathrm{E}$ & Park, Suburban & May 2018 & Scooping/larvae \\
\hline & Shenzhen & SZSK & $22^{\circ} 29^{\prime} \mathrm{N} / 113^{\circ} 54^{\prime} \mathrm{E}$ & Flower nursery, Urban & June 2018 & Scooping/larvae, pupa \\
\hline Guangxi & Nanning & GXNN & $22^{\circ} 47^{\prime} \mathrm{N} / 108^{\circ} 19^{\prime} \mathrm{E}$ & Kindergarten, Urban & May 2020 & Scooping/larvae \\
\hline \multirow[t]{4}{*}{ Hainan } & \multirow[t]{2}{*}{ Haikou } & HNHK94\& & \multirow[t]{2}{*}{$20^{\circ} 02^{\prime} \mathrm{N} / 110^{\circ} 11^{\prime} \mathrm{E}$} & \multirow{2}{*}{$\begin{array}{l}\text { Residential area, Suburban, } \\
\text { Island }\end{array}$} & June 1994 & \multirow[t]{2}{*}{ Scooping/larvae, pupa } \\
\hline & & $\mathrm{HNHK}^{*}$ & & & $\begin{array}{l}\text { June-October } \\
2017\end{array}$ & \\
\hline & $\begin{array}{l}\text { Yongxing } \\
\text { Island }\end{array}$ & HNSS & $16^{\circ} 49^{\prime} \mathrm{N} / 112^{\circ} 20^{\prime} \mathrm{E}$ & Tropic Island & April 2019 & BG-trap/adult \\
\hline & Sanya & HNSY & $18^{\circ} 15^{\prime} \mathrm{N} / 109^{\circ} 30^{\prime} \mathrm{E}$ & Village, Island & June 2019 & Scooping/larvae, pupa \\
\hline Jiangsu & Nanjing & JSNJ & $32^{\circ} 03^{\prime} \mathrm{N} / 118^{\circ} 47^{\prime} \mathrm{E}$ & Park, Urban & October 2017 & Scooping/larvae \\
\hline Sichuan & Chengdu & SCCD $97^{\&}$ & $30^{\circ} 34^{\prime} \mathrm{N} / 104^{\circ} 03^{\prime} \mathrm{E}$ & Park, Suburban & June 1997 & Scooping/larvae, pupa \\
\hline \multirow[t]{2}{*}{ Shandong } & Jinan & SDJNan & $36^{\circ} 39^{\prime} \mathrm{N} / 117^{\circ} 06^{\prime} \mathrm{E}$ & Park, Urban & August 2017 & Scooping/larvae, pupa \\
\hline & Jining & SDJNing & $35^{\circ} 24^{\prime} \mathrm{N} / 116^{\circ} 34^{\prime} \mathrm{E}$ & Village & July 2018 & Scooping/larvae, pupa \\
\hline \multirow{3}{*}{$\begin{array}{l}\text { Shanghai } \\
(\mathrm{SH})\end{array}$} & Baoshan & SHBS* & $31^{\circ} 24^{\prime} \mathrm{N} / 121^{\circ} 29^{\prime} \mathrm{E}$ & Residential area, Suburban & August 2017 & Scooping/larvae \\
\hline & $\begin{array}{l}\text { Yangpu } \\
\text { Park }\end{array}$ & SHGQ & $31^{\circ} 19^{\prime} \mathrm{N} / 121^{\circ} 32^{\prime} \mathrm{E}$ & Park, Urban & $\begin{array}{l}\text { September- } \\
\text { October } 2017\end{array}$ & Scooping/larvae \\
\hline & Yangpu & SHYP* & $31^{\circ} 15^{\prime} \mathrm{N} / 121^{\circ} 31^{\prime} \mathrm{E}$ & $\begin{array}{l}\text { Outdoor area of office building, } \\
\text { Urban }\end{array}$ & $\begin{array}{l}\text { June-October } \\
2017\end{array}$ & BG-trap/adult \\
\hline \multirow[t]{2}{*}{ Shanxi } & Yangquan & \multirow[t]{2}{*}{ SX } & $37^{\circ} 51^{\prime} \mathrm{N} / 113^{\circ} 34^{\prime} \mathrm{E}$ & \multirow[t]{2}{*}{ Residential area, Urban } & \multirow{2}{*}{$\begin{array}{l}\text { June-October } \\
2017\end{array}$} & \multirow[t]{2}{*}{ Scooping/larvae } \\
\hline & Yuncheng & & $35^{\circ} 01^{\prime} \mathrm{N} / 111^{\circ} 0^{\prime} \mathrm{E}$ & & & \\
\hline \multirow[t]{2}{*}{ Shaanxi } & \multirow[t]{2}{*}{ Xian } & \multirow[t]{2}{*}{ SXXA } & \multirow[t]{2}{*}{$34^{\circ} 20^{\prime} \mathrm{N} / 108^{\circ} 56^{\prime} \mathrm{E}$} & \multirow[t]{2}{*}{ Residential area, Urban } & $\begin{array}{l}\text { September- } \\
\text { October } 2017\end{array}$ & Light trap/adult \\
\hline & & & & & $\begin{array}{l}\text { June-October } \\
2018\end{array}$ & Light trap/adult \\
\hline \multirow[t]{2}{*}{ Yunnan } & \multirow[t]{2}{*}{ Jinghong } & \multirow[t]{2}{*}{ YNJH } & \multirow[t]{2}{*}{$22^{\circ} 02^{\prime} \mathrm{N} / 100^{\circ} 47^{\prime} \mathrm{E}$} & \multirow[t]{2}{*}{ Outdoor, Urban } & October 2016 & Scooping/larvae, pupa \\
\hline & & & & & September 2017 & Sucking tube/adult \\
\hline Zhejiang & Hangzhou & ZJHZ* & $30^{\circ} 14^{\prime} \mathrm{N} / 120^{\circ} 12^{\prime} \mathrm{E}$ & $\begin{array}{l}\text { Residential area, Urban; } \\
\text { Surrounding area of } \\
\text { restaurant, Suburban }\end{array}$ & September 2017 & $\begin{array}{l}\text { Scooping/larvae; Sucking } \\
\text { tube/adult }\end{array}$ \\
\hline
\end{tabular}


The allele frequency at codon 1532 and 1534 of VGSC gene in each Aedes albopictus population from China.

\begin{tabular}{|c|c|c|c|c|c|c|c|c|c|c|c|c|c|c|}
\hline \multirow{3}{*}{$\begin{array}{l}\text { Sample } \\
\text { code }\end{array}$} & \multirow{3}{*}{$\begin{array}{l}\text { Sample } \\
\text { size }\end{array}$} & & \multicolumn{2}{|c|}{ Codon 1532} & \multicolumn{10}{|c|}{ Codon 1534} \\
\hline & & & Wildtype & Mutant & Wildtype & Mutant & & & & & & & & \\
\hline & & & ATC/I & $\mathrm{ACC} / \mathrm{T}$ & $\mathrm{TTC} / \mathrm{F}$ & TTG/L & CTG/L & CTC/L & TTA/L & $\mathrm{TCC} / \mathrm{S}$ & TCG/S & $\mathrm{TGC} / \mathrm{C}$ & $\mathrm{CGC} / \mathrm{R}$ & TGG/W \\
\hline \multirow[t]{2}{*}{ BJFT } & \multirow[t]{2}{*}{58} & $N$ & 73 & 43 & 115 & 0 & 0 & 0 & 0 & 1 & 0 & 0 & 0 & 0 \\
\hline & & $\begin{array}{l}P \\
(\%)\end{array}$ & 62.93 & 37.07 & 99.14 & 0 & 0 & 0 & 0 & 0.86 & 0 & 0 & 0 & 0 \\
\hline \multirow[t]{2}{*}{ GDGZ } & \multirow[t]{2}{*}{42} & $N$ & 84 & 0 & 21 & 1 & 0 & 0 & 0 & 60 & 0 & 2 & 0 & 0 \\
\hline & & $\begin{array}{l}P \\
(\%)\end{array}$ & 100.00 & 0 & 25.00 & 1.19 & 0 & 0 & 0 & 71.43 & 0 & 2.38 & 0 & 0 \\
\hline \multirow[t]{2}{*}{ GDST } & \multirow[t]{2}{*}{60} & $N$ & 120 & 0 & 120 & 0 & 0 & 0 & 0 & 0 & 0 & 0 & 0 & 0 \\
\hline & & $\begin{array}{l}P \\
(\%)\end{array}$ & 100.00 & 0 & 100.00 & 0 & 0 & 0 & 0 & 0 & 0 & 0 & 0 & 0 \\
\hline \multirow[t]{2}{*}{ SZSK } & \multirow[t]{2}{*}{60} & $N$ & 120 & 0 & 37 & 26 & 4 & 10 & 0 & 9 & 2 & 21 & 8 & 3 \\
\hline & & $\begin{array}{l}P \\
(\%)\end{array}$ & 100.00 & 0 & 30.83 & 21.67 & 3.33 & 8.33 & 0 & 7.50 & 1.67 & 17.50 & 6.67 & 2.50 \\
\hline \multirow[t]{2}{*}{ GXNN } & \multirow[t]{2}{*}{54} & $N$ & 108 & 0 & 16 & 1 & 0 & 1 & 0 & 47 & 0 & 43 & 0 & 0 \\
\hline & & $\begin{array}{l}P \\
(\%)\end{array}$ & 100.00 & 0 & 14.81 & 0.93 & 0 & 0.93 & 0 & 43.52 & 0 & 39.81 & 0 & 0 \\
\hline \multirow[t]{2}{*}{ HNHK } & \multirow[t]{2}{*}{139} & $N$ & 278 & 0 & 95 & 0 & 0 & 0 & 0 & 172 & 0 & 11 & 0 & 0 \\
\hline & & $\begin{array}{l}P \\
(\%)\end{array}$ & 100.00 & 0 & 34.17 & 0 & 0 & 0 & 0 & 61.87 & 0 & 3.96 & 0 & 0 \\
\hline \multirow[t]{2}{*}{ HNSS } & \multirow[t]{2}{*}{36} & $N$ & 72 & 0 & 26 & 0 & 0 & 0 & 0 & 46 & 0 & 0 & 0 & 0 \\
\hline & & $\begin{array}{l}P \\
(\%)\end{array}$ & 100.00 & 0 & 36.11 & 0 & 0 & 0 & 0 & 63.89 & 0 & 0 & 0 & 0 \\
\hline \multirow[t]{2}{*}{ HNSY } & \multirow[t]{2}{*}{91} & $N$ & 182 & 0 & 119 & 42 & 0 & 1 & 0 & 18 & 0 & 2 & 0 & 0 \\
\hline & & $\begin{array}{l}P \\
(\%)\end{array}$ & 100.00 & 0 & 65.38 & 23.08 & 0 & 0.55 & 0 & 9.89 & 0 & 1.10 & 0 & 0 \\
\hline \multirow[t]{2}{*}{ JSNJ } & \multirow[t]{2}{*}{47} & $N$ & 87 & 7 & 90 & 0 & 0 & 0 & 0 & 4 & 0 & 0 & 0 & 0 \\
\hline & & $\begin{array}{l}P \\
(\%)\end{array}$ & 92.55 & 7.45 & 95.74 & 0 & 0 & 0 & 0 & 4.26 & 0 & 0 & 0 & 0 \\
\hline \multirow[t]{2}{*}{ SDJNan } & \multirow[t]{2}{*}{108} & $N$ & 216 & 0 & 190 & 0 & 0 & 0 & 23 & 3 & 0 & 0 & 0 & 0 \\
\hline & & $\begin{array}{l}P \\
(\%)\end{array}$ & 100.00 & 0 & 87.96 & 0 & 0 & 0 & 10.65 & 1.39 & 0 & 0 & 0 & 0 \\
\hline \multirow[t]{2}{*}{ SDJNing } & 44 & $N$ & 81 & 7 & 88 & 0 & 0 & 0 & 0 & 0 & 0 & 0 & 0 & 0 \\
\hline & & $\begin{array}{l}P \\
(\%)\end{array}$ & 92.05 & 7.95 & 100.00 & 0 & 0 & 0 & 0 & 0 & 0 & 0 & 0 & 0 \\
\hline SHBS & 138 & $N$ & 253 & 23 & 214 & 0 & 0 & 0 & 0 & 62 & 0 & 0 & 0 & 0 \\
\hline & & $\begin{array}{l}P \\
(\%)\end{array}$ & 91.67 & 8.33 & 77.54 & 0 & 0 & 0 & 0 & 22.46 & 0 & 0 & 0 & 0 \\
\hline SHGQ & 126 & $N$ & 207 & 45 & 159 & 0 & 0 & 0 & 0 & 93 & 0 & 0 & 0 & 0 \\
\hline & & $\begin{array}{l}P \\
(\%)\end{array}$ & 82.14 & 17.86 & 63.10 & 0 & 0 & 0 & 0 & 36.90 & 0 & 0 & 0 & 0 \\
\hline SHYP & 98 & $N$ & 161 & 35 & 102 & 2 & 0 & 0 & 0 & 91 & 1 & 0 & 0 & 0 \\
\hline & & $\begin{array}{l}P \\
(\%)\end{array}$ & 82.14 & 17.86 & 52.04 & 1.02 & 0 & 0 & 0 & 46.43 & 0.51 & 0 & 0 & 0 \\
\hline SX & 62 & $N$ & 115 & 9 & 123 & 0 & 0 & 0 & 0 & 1 & 0 & 0 & 0 & 0 \\
\hline & & $\begin{array}{l}P \\
(\%)\end{array}$ & 92.74 & 7.26 & 99.19 & 0 & 0 & 0 & 0 & 0.81 & 0 & 0 & 0 & 0 \\
\hline SXXA & 25 & $N$ & 32 & 18 & 50 & 0 & 0 & 0 & 0 & 0 & 0 & 0 & 0 & 0 \\
\hline
\end{tabular}




\begin{tabular}{|c|c|c|c|c|c|c|c|c|c|c|c|c|c|c|}
\hline & & $\begin{array}{l}P \\
(\%)\end{array}$ & 64.00 & 36.00 & 100.00 & 0 & 0 & 0 & 0 & 0 & 0 & 0 & 0 & 0 \\
\hline \multirow[t]{2}{*}{ YNJH } & 77 & $N$ & 144 & 10 & 72 & 4 & 0 & 0 & 0 & 73 & 1 & 4 & 0 & 0 \\
\hline & & $\begin{array}{l}P \\
(\%)\end{array}$ & 93.51 & 6.49 & 46.75 & 2.60 & 0 & 0 & 0 & 47.40 & 0.65 & 2.60 & 0 & 0 \\
\hline \multirow[t]{2}{*}{ ZJHZ } & 284 & $N$ & 567 & 1 & 48 & 0 & 0 & 0 & 0 & 520 & 0 & 0 & 0 & 0 \\
\hline & & $\begin{array}{l}P \\
(\%)\end{array}$ & 99.82 & 0.18 & 8.45 & 0 & 0 & 0 & 0 & 91.55 & 0 & 0 & 0 & 0 \\
\hline \multirow[t]{2}{*}{ Total } & 1549 & $N$ & 2900 & 198 & 1685 & 76 & 4 & 12 & 23 & 1200 & 4 & 83 & 8 & 3 \\
\hline & & $\begin{array}{l}P \\
(\%)\end{array}$ & 93.61 & 6.39 & 54.39 & 2.45 & 0.13 & 0.39 & 0.74 & 38.73 & 0.13 & 2.68 & 0.26 & 0.10 \\
\hline
\end{tabular}

\subsection{Annual average temperature of collection sites}

The annual average temperature (AAT) of collection sites were search and recorded from China National Meteorological Science Data Center (http://data.cma.cn) (Table S1).

\subsection{DNA extraction}

Genomic DNA was extracted from adult mosquitoes using DNAzol Reagent (Invitrogen, USA) according to the manufacturer's instructions. In brief, a single mosquito was put in a $1.5 \mathrm{~mL}$ eppendorf tube, and powdered efficiently by firstly freezing in liquid nitrogen. Then $100 \mu \mathrm{L} D N A z o l$ were added to lysis, and the supernatant was moved to another eppendorf tube. After adding $50 \mu \mathrm{L}$ ethanol, the mixed solution was stored at $-20^{\circ} \mathrm{C}$ overnight. The DNA in the solution was adsorbed through a nucleic acid adsorption column. After washing with $70 \%$ ethanol, the DNA was eluted from the column with $\mathrm{ddd} \mathrm{H}_{2} \mathrm{O}$. The concentration of the DNA was quantified using $\mathrm{OD}_{280}$ absorption.

\subsection{PCR and $\mathrm{kdr}$ alleles detection}

A fragment of approximately 350 bp of S6 segment in the VGSC gene domain III was amplified using PCR kit (Aidlab, China) and sequenced. The primers are aegSCF7 (5'-AGG TAT CCG AAC GTT GCT GT-3') and aegSCR8 (5'-TAG CTT TCA GCG GCT TCT TC-3') $(12,16)$. PCR reaction was carried out in a Verity 96 well 157 Thermal Cycler (Applied Biosystems, USA). The cycling parameter included an initial step of denaturation at $94^{\circ} \mathrm{C}$ for 2 min, followed by 35 cycles of amplification at $94^{\circ} \mathrm{C}$ for $30 \mathrm{~s}, 52^{\circ} \mathrm{C}$ for $30 \mathrm{~s}$, and $72^{\circ} \mathrm{C}$ for $30 \mathrm{~s}$, followed by a final extension step at $72^{\circ} \mathrm{C}$ for 8 min. After electrophoresis, $\mathrm{PCR}$ products were purified and sequenced from both directions. Sequences were aligned and analyzed by DNASTAR Lasergene 12.0 software (35).

\subsection{Parsimony network the haplotypes of VGSC gene}

The haplotypes of VGSC gene were recorded and the networks was constructed based on statistical parsimony using TCS 1.21 software (36).

\subsection{Statistical analyses}

The allele frequency of $k d r$ mutations was calculated as:

$$
\mathrm{R}=\frac{k}{n \times 2} \times 100 \%
$$

"R" means the allele frequency. " $k$ " represents the number of alleles, and " $n$ " represents the sample size.

The mutation frequency was defined as the frequency of wildtype-mutant heterozygotes and mutant-mutant homozygotes, which was calculated as:

$$
\mathrm{M}=\frac{a+b}{n} \times 100 \%
$$

"M" means the mutation frequency. "a" represents the number of wildtype-mutant samples, and " $b$ " represents the number of mutant-mutant samples. " $n$ " is the sample size.

The correlation between the AAT of the collection site and the kdr mutation rate was analyzed by Pearson Correlation using SPSS 21.0. The difference of the mutation rate between groups was calculated by one-way ANOVA using SPSS 21.0.

\section{Results}

\subsection{Mosquito samples}

A total of 1549 Ae. albopictus adults were collected from 18 sites in China from 2017 to 2019 (Table 2). The kdrinformation of 5 populations (SD JNan, SHBS, SHYP, ZJHZ, HNHK) has been reported in our previous work $(12,30)$.

\subsection{F1534 mutation pattern}




\subsubsection{F1534 mutation rate at codon}

The wildtype codon at codon 1534 is TTC (F). The overall frequency of mutant allele F1534 is $45.62 \%$, which is the site with the most mutation frequency and types in VGSC of Ae. albopictus. A total of nine mutant alleles were detected, namely TCC/TCG (S) (38.86\%), TTG/CTG/CTC/TTA (L) (3.71\%), TGC (C) (2.68\%), CGC (R) $(0.27 \%)$ and TGG (W) (0.10\%). The mutant allele TCC has the highest frequency (38.74\%), whereas the lowest frequency allele is TGG (0.10\%) (Fig. 1, Table 2). A total of 15 genotypes were detected (Table S2), including the wildtype genotype F/F, four wildtype-mutant heterozygotes F/L, F/S, $\mathrm{F} / \mathrm{C}$ and F/R, and ten mutant genotypes $\mathrm{L} / \mathrm{L}, \mathrm{C} / \mathrm{C}, \mathrm{S} / \mathrm{S}, \mathrm{C} / \mathrm{R}, \mathrm{L} / \mathrm{C}, \mathrm{L} / \mathrm{R}, \mathrm{C} / \mathrm{W}, \mathrm{S} / \mathrm{R}, \mathrm{L} / \mathrm{S}$ and S/C. The frequencies of wildtype genotype, wildtype-mutant heterozygote and mutant genotype were $40.61 \%, 27.57 \%$ and $31.82 \%$, respectively (Table S2). In other words, $59.39 \%$ of Ae. albopictus adults have mutations at 1534 codon of the VGSC gene.

\subsubsection{F1534 mutation pattern in the field populations}

In the eighteen field populations, fifteen populations have F1534 mutations (Table 2). The highest frequency was in ZJHZ (91.55\%), followed by GXNN (85.19\%), GDGZ (75.00\%), SZSK (69.17\%), HNHK (65.83\%), HNSS (63.89\%) and YNJH (53.25\%), and eight populations with frequencies below 50\%. Three populations have no mutant in 1534 including GDST, SXXA and SDJNing. (Table 2).

In terms of the mutant allele types, the SZSK population carried the most types with eight mutant alleles, followed by GXNN, YNJH and HNSY with 4 mutant alleles, GDGZ and SHYP with 3 mutant alleles, HNHK and SDJNan with 2 mutant alleles. For the other seven populations, only one mutant allele as F1534S/TCC was detected (Table 2).

$1534 \mathrm{TCC} / \mathrm{S}$ is the most common mutant allele, which was detected in all of the 15 populations. A total of four mutant alleles were found in only one population, namely CTG/L, CGC/R, TGG/W and TTA/L. Among them, CTG/L (3.33\%), CGC/R (6.67\%) and TGG/W (2.50\%) were only found in SZSK, and TTA/L (10.65\%) was identified in the SDJNan.

\subsection{I1532 mutation pattern}

\subsubsection{1532 mutation rate at codon}

Except for the wildtype alleles ATC (I), only one mutant allele ACC (T) was found at codon 1532 (Table 2). Compare to 1534 codon, the 1532 codon have much lower mutation frequency with $6.39 \%$. Three genotypes were found, as wildtype genotype I/I (88.57\%), wildtype-mutant heterozygote I/T (10.07\%) and mutant genotype $\mathrm{T} / \mathrm{T}(1.36 \%)$ (Table S3).

\subsubsection{F1532 mutation pattern in the field populations}

The mutant allele I1532T was detected in ten field populations, as YNJH, BJFT, SDJNing, SHBS, SHYP, SHGQ, ZJHZ, SXXA, JSNJ and SX. The highest frequency was $37.07 \%$ in the BJFT population, followed by $36.00 \%$ in the SXXA population (Table 2, Fig. 2). The mutant homozygous 1532 T/T was found in six populations, namely BJFT (13.79\%), SXXA (12.00\%), SHYP (5.10\%), SHGQ (2.38\%), SDJNing (2.27\%) and SHBS (0.72\%) (Table S3).

\subsection{Multiple mutations at codon 1532 and 1534}

Multiple mutations at 11532 and F1534 appeared in five populations as YNJH, SHBS, SHYP, SHGQ and ZJHZ (Fig S3). The highest frequency of cooccurrence of the mutations was $21.43 \%$ in SHYP population, followed by $15.08 \%$ (SHGQ). Three types of combined mutations were present, as I/T + F/S, I/T $+\mathrm{S} / \mathrm{S}, \mathrm{T} / \mathrm{T}+\mathrm{F} / \mathrm{L}$. However, no individuals with mutant homozygotes at both codons were found (Table 3 ).

Table 3

Frequency of co-occurrence of I1532T + F1534S genotypes of VGSC gene in the Aedes albopictus populations from China.

\begin{tabular}{|lllllll|}
\hline Loci & \multicolumn{5}{l|}{ Population } \\
\hline I1532 & F1534 & SHBS & SHGQ & SHYP & YNJH & ZJHZ \\
\hline I/T & F/S & $5(3.62 \%)$ & $19(15.08 \%)$ & $19(19.39 \%)$ & $6(7.79 \%)$ & 0 \\
\hline I/T & S/S & 0 & 0 & 0 & 0 & $1(0.35 \%)$ \\
T/T & F/L & 0 & 0 & $2(2.04 \%)$ & 0 & 0 \\
\hline Note: The number in brackets is the percentage of co-occurrence of I1532T + F1534S genotype.
\end{tabular}

\subsection{Geographic distribution of kdr mutants of Ae. albopictus in China}

Interestingly, the pattern of $k d r$ mutations in Ae. albopictus seems to be related to geographical factors. F1534S/L/C/R/W mutant alleles were mainly found from southern and central China (Fig. 2A), while I1532T was mainly found in populations from northern and central China (Fig. 2B). If the field populations were divided to the southern group and the northern group by $32^{\circ} \mathrm{N}$ (Fig. 2), there is a significant difference in the 1534 mutation rate $(p=0.0003)$ and the 1532 mutation rate $(p=0.0443)$ between the two groups.

To further explore the phenomenon, we collected the AAT of the collection sites. The 1534 mutation rate was significantly positive related to AAT (Coefficient $=0.624, p=0.0056$ ), while the 1532 mutation rate was significantly negative related to AAT (Coefficient $=-0.645, p=0.0038$ ). 
It is worth noting that the ZJHZ population was collected during the 2019 Hangzhou dengue fever epidemic. At that time, a large number of insecticides had been used, so the collected mosquitoes were likely to be a screened resistant population. The collection site of the GDST population is very close to the sea. It was learned that almost no pesticides was used in the local area through oral interviews. If the ZJHZ and GDST population were removed from the correlation analysis, the 1534 mutation rate showed more significantly positive related to AAT (Coefficient $=0.843, p<0.0001$ ), and the 1532 mutation rate was also significantly negative related to AAT (Coefficient $=-0.657, p=0.0057$ ).

\subsection{Genealogical relationships among the haplotypes of VGSC gene}

Based on the alleles in codons 1532 and 1534, thirteen haplotypes were inferred, which has been submitted to the NCBI (https://www.ncbi.nlm.nih.gov/) (Table 4). The 95\% parsimony network showed a parallel evolution pathway. The ancestral wildtype haplotype (H01_IF) weight was only 0.13. Six mutant haplotypes were formed by one step mutation from ancestral haplotype, as H02_IL, H04_IL, H05_IL, H06_IS, H08_IC and H11_TF. The other six haplotypes were formed by one more mutation (Fig. 3). This result supports the view that kdrmutations of Ae. albopictus have multiple origins.

Table 4

Haplotype of VGSC gene according mutant alleles of codons 1532 and 1534 in Aedes albopictus populations from China.

\begin{tabular}{|llll|}
\hline Haplotype & Allele & \multicolumn{2}{c|}{ GenBank Submission Number } \\
\cline { 2 - 3 } & Codon 1532 & Codon 1532 & \\
\hline H01_IF & I/ATC & F/TTC & MT559317 \\
\hline H02_IL & I/ATC & L/TTG & MT559318 \\
\hline H03_IL & I/ATC & L/CTG & MT559319 \\
\hline H04_IL & I/ATC & L/CTC & MT559320 \\
H05_IL & I/ATC & L/TTA & MT559321 \\
\hline H06_IS & I/ATC & S/TCC & MT559322 \\
\hline H07_IS & I/ATC & S/TCG & MT559323 \\
H08_IC & I/ATC & C/TGC & MT559324 \\
\hline H09_IR & I/ATC & R/CGC & MT559325 \\
\hline H10_IW & I/ATC & W/TGG & MT559326 \\
\hline H11_TF & T/ACC & F/TTC & MT559327 \\
\hline H12_TL & T/ACC & L/TTG & MT559328 \\
\hline H13_TS & T/ACC & S/TCC & MT559329 \\
\hline
\end{tabular}

\subsection{Historic change of kdr mutants in Ae. albopictus in China}

A total of 50 individuals from three sites in the 1990s were collected to explore the historic change of the $k d r$ mutation, including HNHK94 (Haikou, $1994, \mathrm{n}=$ 12), GDGZ95 (Guangzhou, 1995, $\mathrm{n}=18$ ) and SCCD97 (Chengdu, 1997, $\mathrm{n}=20$ )). No mutant allele was detected at codon 1532 of VGSC gene. However, F1534S/TCC was found in HNHK94 with an unexpected frequency of 100\%. HNHK94 samples were collected from Haikou in 1994 , when 15 years earlier than the firstly reported $k d r$ mutant populations by Kasai et al (16). Although the number of samples available is limited, the result clearly showed that the F1534S kdrmutation of Ae. albopictus appeared no later than 1994.

\subsection{Synonymous mutations}

In addition to above non-synonymous mutations, we also found 5 synonymous mutations at codon 1516 CCG (P), 1528 TTC (F), 1539 ACC (T), 1540 CTC (L) and $1541 \mathrm{AAC}(\mathrm{N})$ in the fragment. Only one mutant allele was detected at codons 1516 (CCA), 1528 (TTT) and 1541 (AAT), respectively, while two mutant alleles were found at codons 1539 (ACG, ACT) and 1540 (CTT, CTG). The frequencies of the mutation alleles were 20.80\% (1516), 8.85\% (1528), 3.78\% (1539), 50.96\% (1540) and 51.52\% (1541) (Table S4). However, we did not find any correlation between these synonymous mutations and non-synonymous mutations at codon 1534 and 1532 . The role of these synonymous mutations remains to be explored.

\section{Discussion}

Insecticide resistance has become an important threat to the control of diseases transmitted by Ae. albopictus. In this study, we collected the field populations of $A e$. albopictus in China, detected and analyzed the $k d r$ mutation to explore the characteristics and possible evolution trend of the $k d r$ mutations. The sample collection sites covered the main distribution range of Ae. albopictus in China from $16^{\circ} \mathrm{N}$ to $40^{\circ} \mathrm{N}$ in this study (6). The climate includes tropical, subtropical and temperate climates.

The results showed that types of $k d r$ mutations have appeared widely in the field populations of Ae. albopictus in China. Certain population (SZSK) showed a high mutation rate of 1534 with complex mutation types. Moreover, two novel mutant alleles F1534W/TGG and F1534R/CGC were detected in SZSK population. The AAT of this group collection point is relatively high $\left(23.0^{\circ} \mathrm{C}\right)$, where mosquitoes reproduce all year round. Moreover, developed trade and 
logistics, high population mobility, and frequently used pesticides in Shenzhen are all factors that promote insecticide resistance in mosquito populations (37). If the use of pesticides cannot be controlled, the high frequency and multiple types of 1534 mutations appeared in SZSK population may be the trend of $k d r$ mutations in the field populations of Ae. albopictus in the future.

An extremely high mutation rate of 1534 was detected in the HNHK94 population collected in Haikou City in 1994, indicating that some populations of Ae. albopictus had high insecticide resistance decades ago. The result pushed the discovery time of kdrmutation in Ae. albopictus samples forward by 15 years (16). The phenomenon may be related to the large-scale use of pesticides in Hainan Province after three dengue fever outbreaks in the last century, as 1979 1982, $1985 \sim 1988,1991$ (38). The ZJHZ population was also collected after the occurrence of dengue fever in Hangzhou (11), which similarly showed a very high percentage of 1534 mutation rates, suggesting that the large-scale use of pesticides is a "closely related" factor for the 1534 mutation rate of the Ae. albopictus population. Therefore, a more cautious, precise and strict insecticide resistance management (IRM) is urgently to be established (39).

In northern populations where the average temperature was low, the $k d r$ mutation rate of $A$ e. albopictus was generally low, and the I1532 mutation rate was relatively high. However, in the southern populations with higher average temperature, the kdrmutation rate was higher, and the F1534 mutation rate was relatively high. Research on the correlation between gene mutations and insecticide resistance showed that F1534S and F1534C were significantly related to insecticide resistance $(12,21)$, while the correlation between I1523T and insecticides was still unclear $(12,32)$. The results of this study clearly show that the southern population is more resistant to pesticides than the northern population. The temperature in the south is high, and mosquitoes have more generations, which can be regarded as fast-evolving populations, while the northern populations can be regarded as slow-evolving populations. The results in this study suggested that the highly resistant population may be screened out in a relatively short period of time in the fast-evolving populations. Due to the long cold winter in the north, pesticides are often used seasonally, which may slow down the development of pesticide resistance. This suggests that seasonal use of pesticides may be a strategy to slow down the development of pesticide resistance. However, how to use insecticides seasonally in a certain area and effectively control the risk of vector-borne disease transmission requires further research. This is very important for the prevention and control of mosquito-borne diseases in the context of global climate change (40).

Although some meaningful results were obtained, there are still some limitations in this study. First, there are only a few historical samples available, which make it impossible to systematically analyze the historical changes of kdrmutations. In addition, accurate information on the use of insecticides cannot be collected, which affected the interpretation of the results. Moreover, this study focused on the most common kdrmutations in Ae. albopictus, leaving some types of $k d r$ mutations with low mutation rate (18). Finally, although the synonymous mutations and intron length polymorphisms have been documented in the populations of Ae. albopictus and $\operatorname{Ae}$. $\operatorname{aegypti}(19,28,41)$, the significance of the synonymous mutations found in this study is not clear, and further research is needed.

\section{Conclusions}

From this study, we can found the kdrmutations are widespread in the field populations of Ae. albopictus in China. Two novel mutant alleles F1534W/TGG and F1534R/CGC were the detected for the first time. The 1534 kdrmutation appeared in the population of Ae. albopictus no later than 1994 . HNHK94 was the earliest known Ae. albopictus field population with kdrmutation. F1534 mutation rate is positive correlated to AAT, while I1532 mutation rate is negative correlated to AAT. Insecticide using should be carefully managed to slow down the spread of high-resistance Ae. albopictus populations.

\section{Abbreviations}

VGSC

voltage-gated sodium channel;

$k d r$

knockdown resistance;

WHO

World Health Organization;

AAT

Annual Average temperature;

CDC

Center for Disease Control and Prevention;

IRM

insecticide resistance management.

\section{Declarations}

\section{Competing interests and consent to participate}

The authors declare that they have no competing interests.

\section{Consent for publication}

Not applicable. 
The datasets used and/or analyzed during the current study are available from the corresponding authors on reasonable request, and sequences are available in GenBank.

\section{Acknowledgements}

We are grateful to Pei-En Leng and Xiao-Qing Lin (SH), Li-Nong Yao (ZJHZ), Hai-Tao Huang, Jian-Bin Wu and Fang Cai (HN), Zhenzhou Yang (BJFT), Jinyong Jiang (YNJH), Li Zhang (SDJNan), Jingxia Cheng (SX), who provided field assistance in the study.

\section{Authors' contributions}

All authors contributed to the collection of mosquitoes. YM and HP designed the study. MC, HD, HY, JB, JG, HM and HP did the experiment and performed data analysis. QZ, FT, HP and YM wrote the manuscript. All authors read and approved the final manuscript.

\section{Funding}

This work was supported by grants from Natural Science Foundation of Shanghai (No. 19ZR1469600 to HP), National Natural Sciences Foundation of China (No. 31970445 to YM) and the Infective Diseases Prevention and Cure Project of China (No. 2017ZX10303404 to YM).

\section{Consent for publication}

Not applicable.

\section{Competing interests}

The authors declare that they have no competing interests.

\section{Ethics approval and consent to participate}

Not applicable.

\section{References}

1. Bhatt S, Gething PW, Brady OJ, Messina JP, Farlow AW, Moyes CL, et al. The global distribution and burden of dengue. Nature. 2013;496(7446):504-7.

2. Liu Q. [Dengue fever in China: new epidemical trend, challenges and strategies for prevention and control.]. Chinese Journal of Vector Biology Control. 2020;31(1):1-6.

3. Du JW, Pan XH. [Prevalent status and features of dengue fever in China]. Chinese Journal of Epidemiology. 2010;31(12):1429-33.

4. Wellekens K, Betrains A, De Munter P, Peetermans W. Dengue: current state one year before WHO 2010-2020 goals. Acta clinica Belgica. $2020: 1-9$.

5. Lambrechts L, Scott TW, Gubler DJ. Consequences of the expanding global distribution of Aedes albopictus for dengue virus transmission. PLoS Negl Trop Dis. 2010;4(5):e646.

6. Yang S, Liu Q. [Trend in global distribution and spread of Aedes albopictus]. Chinese Journal of Vector Biology Control. 2013;24(1):1-4.

7. Meng F, Wang Y, Feng L, Liu Q. [Review on dengue prevention and control and integrated mosquito management in China]. Chinese Journal of Vector Biology Control. 2015;26(1):4-10.

8. Lin H, Wang X, Li Z, Li K, Lin C, Yang H, et al. Epidemiological characteristics of dengue in mainland China from 1990 to 2019: A descriptive analysis. Medicine. 2020;99(36):e21982.

9. Wang Y, Jiang Z. [Development and application of public health pesticides in China, 2013-2016.]. Chinese Journal of Vector Biology Control. 2016;27(1):421-5.

10. Li Y, Zhou G, Zhong D, Wang X, Hemming-Schroeder E, David RE, et al. Widespread multiple insecticide resistance in the major dengue vector Aedes albopictus in Hainan Province, China. Pest management science. 2020.

11. Hou J, Liu Q, Wang J, Wu Y, Li T, Gong Z. Insecticide Resistance of Aedes albopictus in Zhejiang Province, China. Bioscience trends. 2020;14(4):248-54.

12. Gao JP, Chen HM, Shi H, Peng H, Ma YJ. Correlation between adult pyrethroid resistance and knockdown resistance (kdr) mutations in Aedes albopictus (Diptera: Culicidae) field populations in China. Infectious diseases of poverty. 2018;7.

13. Narahashi T. Neuronal ion channels as the target sites of insecticides. Pharmacology toxicology. 1996;79(1):1-14.

14. Silva JJ, Scott JG. Conservation of the voltage-sensitive sodium channel protein within the Insecta. Insect molecular biology. 2020;29(1):9-18.

15. Scott JG. Life and Death at the Voltage-Sensitive Sodium Channel: Evolution in Response to Insecticide Use. Ann Rev Entomol. $2019 ; 64: 243-57$.

16. Kasai S, Ng LC, Lam-Phua SG, Tang CS, Itokawa K, Komagata O, et al. First detection of a putative knockdown resistance gene in major mosquito vector, Aedes albopictus. Jpn J Infect Dis. 2011;64(3):217-21.

17. Auteri M, La Russa F, Blanda V, Torina A. Insecticide Resistance Associated with kdr Mutations in Aedes albopictus: An Update on Worldwide Evidences. BioMed research international. 2018;2018:3098575.

18. Kasai S, Caputo B, Tsunoda T, Cuong TC, Maekawa Y, Lam-Phua SG, et al. First detection of a Vssc allele V1016G conferring a high level of insecticide resistance in Aedes albopictus collected from Europe (Italy) and Asia (Vietnam), 2016: a new emerging threat to controlling arboviral diseases.

Eurosurveillance. 2019;24(5):48-59. 
19. Xu J, Bonizzoni M, Zhong D, Zhou G, Cai S, Li Y, et al. Multi-country Survey Revealed Prevalent and Novel F1534S Mutation in Voltage-Gated Sodium Channel (VGSC) Gene in Aedes albopictus. PLoS Negl Trop Dis. 2016;10(5):e0004696.

20. Aguirre-Obando OA, Martins AJ, Navarro-Silva MA. First report of the Phe1534Cys kdr mutation in natural populations of Aedes albopictus from Brazil. Parasites \& vectors. 2017;10.

21. Chen H, Li K, Wang X, Yang X, Lin Y, Cai F, et al. First identification of kdrallele F1534S in VGSC gene and its association with resistance to pyrethroid insecticides in Aedes albopictus populations from Haikou City, Hainan Island, China. Infectious diseases of poverty. $2016 ; 5: 31$.

22. Wang $X$, Chen H, Yang X, Lin Y, Cai F, Zhong W, et al. [Resistance to pyrethroid insecticides and analysis of knockdown resistance ( $k d r)$ gene mutations in Aedes albopictus from Haikou City]. Academic Journal of Second Military Medical University. 2015;36(8):832-8.

23. Zhu CY, Zhao CC, Wang YG, Ma DL, Song XP, Wang J, et al. Establishment of an innovative and sustainable PCR technique for 1534 locus mutation of the knockdown resistance $(k d r)$ gene in the dengue vector Aedes albopictus. Parasites \& vectors. 2019;12(1):603.

24. Li Y, Xu J, Zhong D, Zhang H, Yang W, Zhou G, et al. Evidence for multiple-insecticide resistance in urban Aedes albopictus populations in southern China. Parasites vectors. 2018;11(1):4.

25. Zhao C, Zhu C, Kai W, Liu G, Liu Q, Lin L, et al. [Genotypes of knockdown resistance gene and their distribution in Aedes albopictus in Haikou, China, in 2018.]. Chinese Journal of Vector Biology Control. 2019;30(1):7-11.

26. Lan X, Xu J, Jiang J. [An analysis of voltage-gated sodium channel gene mutation in Aedes albopictus resistant populations against pyrethroid insecticides in Ruili, Yunnan Province, China.]. Chinese Journal of Vector Biology Control. 2019;30(2):158-62.

27. Zhu C, Zhao C, Lun X, Zhu J, Li H, Jiang J, et al. [Distribution of knockdown resistance genotypes in Aedes albopictus in Jinghong, Yunnan Province, China, 2018-2019.]. Chinese Journal of Vector Biology Control. 2020;31(1):7-11.

28. Zhou XJ, Yang C, Liu N, Li M, Tong Y, Zeng XP, et al. Knockdown resistance ( $k d r$ ) mutations within seventeen field populations of Aedes albopictus from Beijing China: first report of a novel V1016G mutation and evolutionary origins of kdr haplotypes. Parasites \& vectors. $2019 ; 12$.

29. Liu HM, Liu LH, Cheng P, Yang LL, Chen JH, Lu Y, et al. Bionomics and insecticide resistance of Aedes albopictus in Shandong, a high latitude and highrisk dengue transmission area in China. Parasites \& vectors. 2020;13(1).

30. Chen H, Gao J, Jiang J, Peng H, Ma Y. [Detection of the I1532 and F1534 kdrmutations and a novel mutant allele I1532T in VGSC gene in the field populations of Aedes albopictus from China.]. Chinese Journal of Vector Biology Control. 2018;29(2):120-5.

31. Gao J, Chen H, Ma Y. Establishment of diagnostic doses of three pyrethroid insecticides for detecting resistance in Aedes albopictus (Diptera: Culicidae) in China. Acta Entomologica Sinica. 2018;61(1):18-24.

32. Yan R, Zhou Q, Xu Z, Zhu G, Dong K, Zhorov BS, et al. Three sodium channel mutations from Aedes albopictus confer resistance to Type I, but not Type II pyrethroids. Insect Biochem Mol Biol. 2020;123:103411.

33. Lu B, [Fauna Sinica I. Diptera, Culicidae I]. Vol. 9. Beijing: Science Press; 1997.

34. Manni M, Gomulski LM, Aketarawong N, Tait G, Scolari F, Somboon P, et al. Molecular markers for analyses of intraspecific genetic diversity in the Asian Tiger mosquito, Aedes albopictus. Parasites \& vectors. 2015;8.

35. Burland TG. DNASTAR's Lasergene sequence analysis software. Methods in molecular biology. 2000;132:71-91.

36. Clement M, Posada D, Crandall KA. TCS: a computer program to estimate gene genealogies. Molecular ecology. 2000;9(10):1657-9.

37. Huang YW, Peng SQ, Lian CL. [Survey on Mosquito at Shenzhen Shekou Port]. Chinese Journal of Frontier Health Quarantine. 2010;2:112-4.

38. Wang CZ, Chen WZ. [Overview of Dengue Fever Prevalence in Hainan Province.]. Hainan Medical Journal. 1992;3(3):1-4.

39. Dusfour I, Vontas J, David JP, Weetman D, Fonseca DM, Corbel V, et al. Management of insecticide resistance in the major Aedes vectors of arboviruses: Advances and challenges. PLoS Negl Trop Dis. 2019;13(10):e0007615.

40. Tidman R, Abela-Ridder B, de Castaneda RR. The impact of climate change on neglected tropical diseases: a systematic review. Trans R Soc Trop Med Hyg. 2021;115(2):147-68.

41. Chung HH, Cheng IC, Chen YC, Lin C, Tomita T, Teng HJ. Voltage-gated sodium channel intron polymorphism and four mutations comprise six haplotypes in an Aedes aegypti population in Taiwan. PLoS Negl Trop Dis. 2019;13(3):e0007291.

\section{Figures}




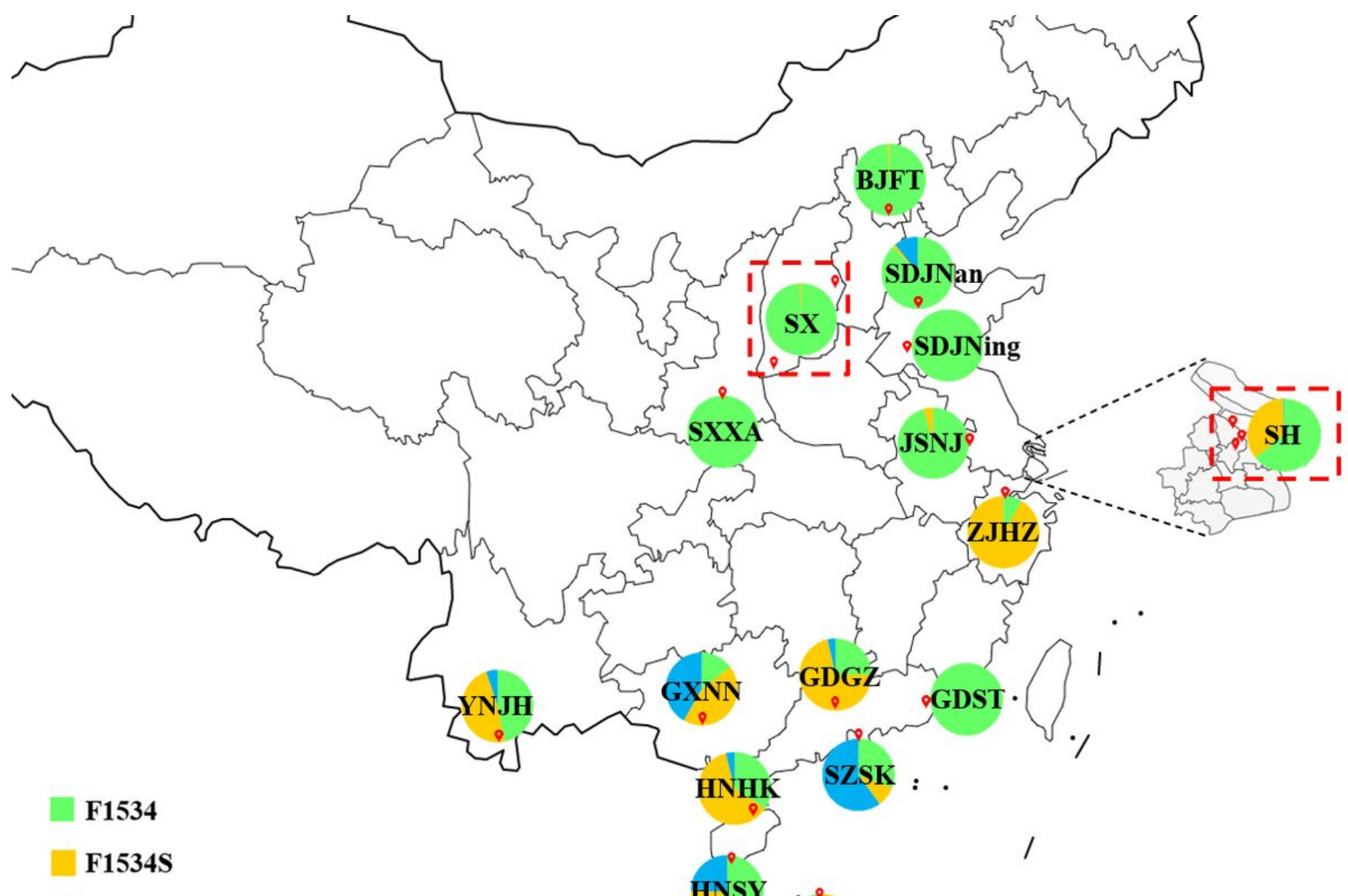

F1534L/C/R/W

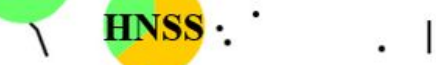

Figure 1

A schematic map of collection sites for Aedes albopictus in China and the composition of the codon 1534 alleles of VGSC gene in the samples. The red balloons indicate the sampling sites (see Table 1 for details). The codon 1534 alleles composition in each site was displayed by a pie chart with green as wildtype F1534, yellow as mutant allele F1534S and blue as mutant allele F1534L/C/R/W (see Table 2 for details). Note: The designations employed and the presentation of the material on this map do not imply the expression of any opinion whatsoever on the part of Research Square concerning the legal status of any country, territory, city or area or of its authorities, or concerning the delimitation of its frontiers or boundaries. This map has been provided by the authors. 
A

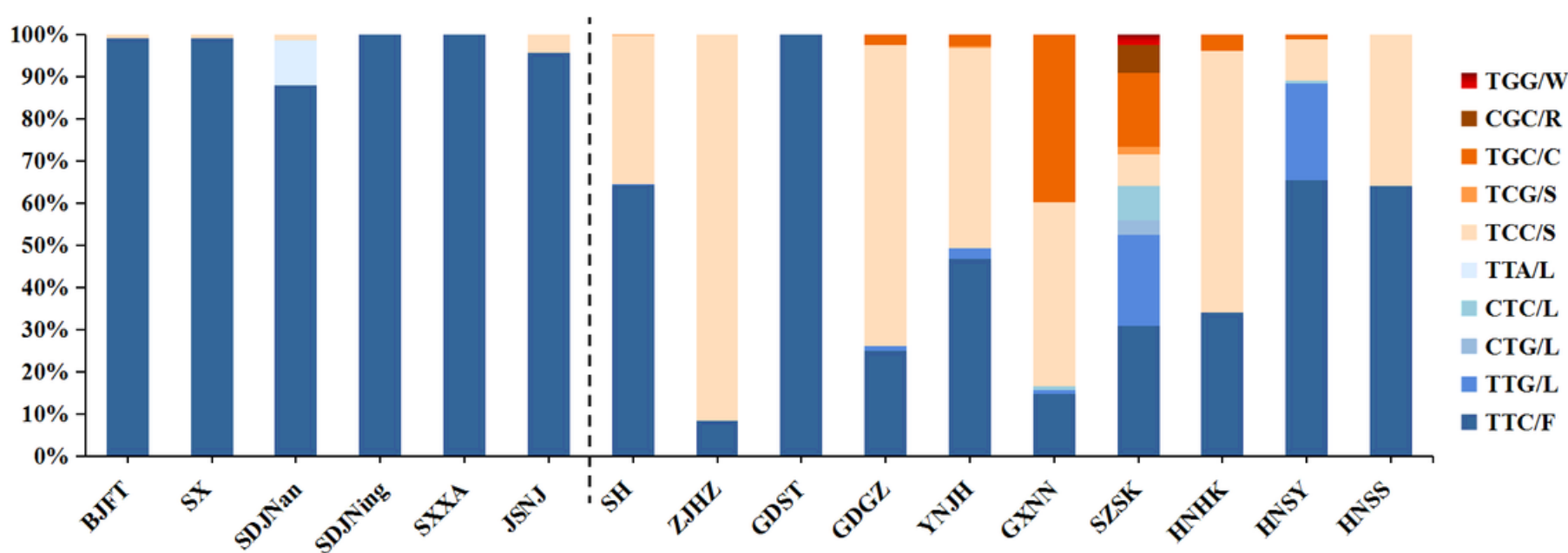

B

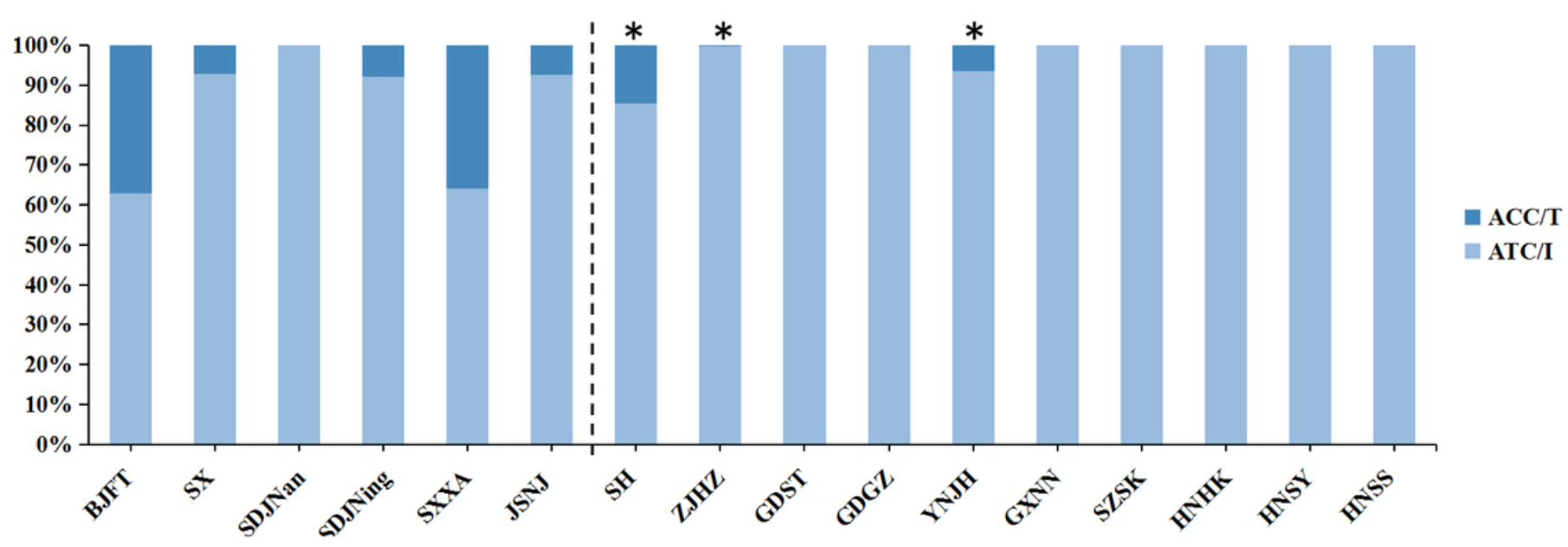

Figure 2

The histogram of allele frequency at codon 1532 (A) and 1534 (B) of VGSC gene in Aedes albopictus populations. SH was the pool of three populations (SHBS, SHYP, SHGQ). For information details, see Table 1 and Table 2. The populations on the left of the dotted line were from central and northern China, and the populations on the right side were from southern China. Horizontal axis indicates the populations while vertical axis denotes the allele frequency. The populations with asterisk was co-occurrence of mutations both codons 1532 and 1534 . 


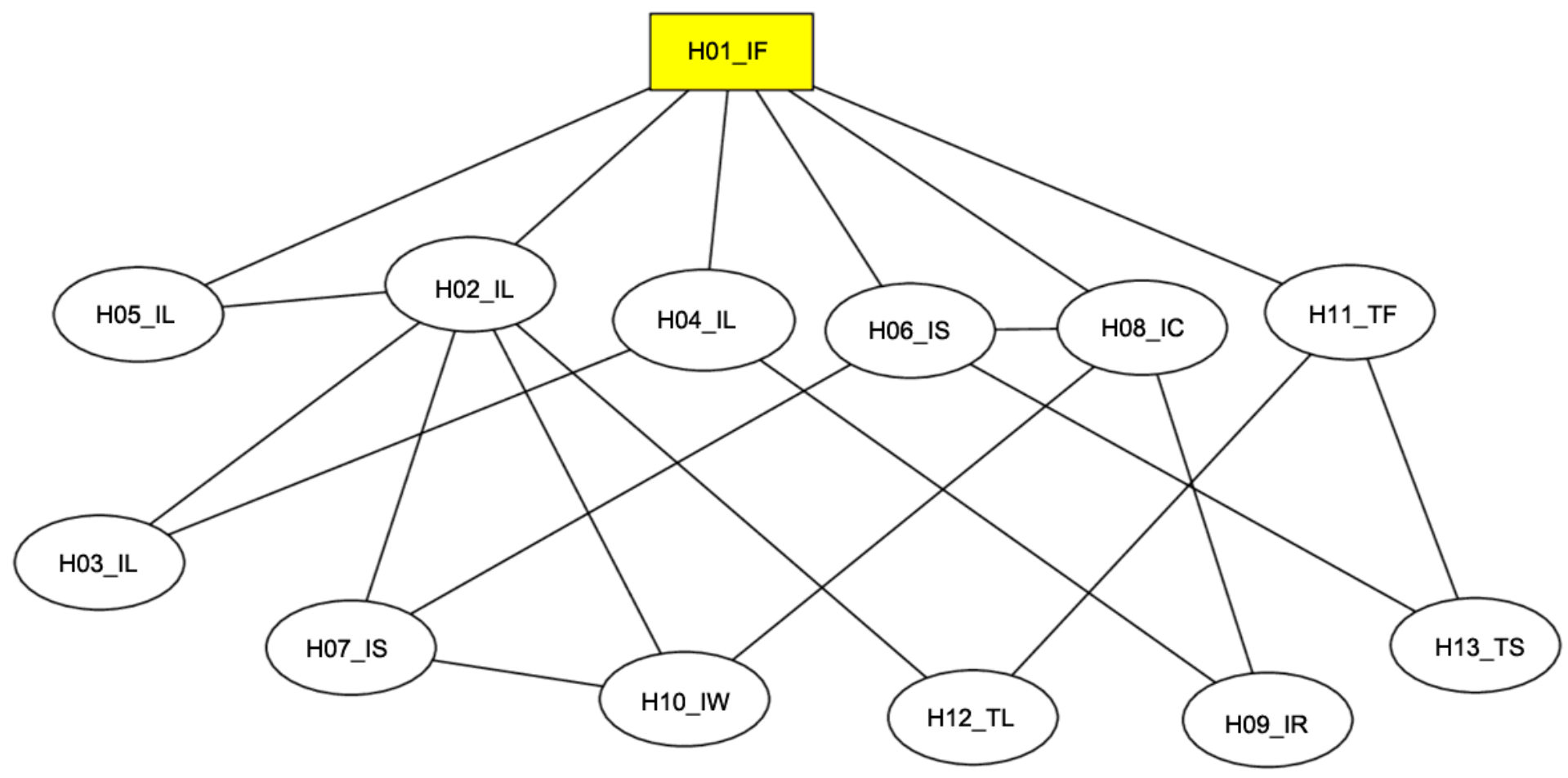

Figure 3

Genealogical relationships among haplotypes of kdr mutations of VGSC gene estimated by TCS. The circle indicates one of haplotypes and the number in each circle represents the haplotype type. The yellow square indicates the wildtype haplotype. Every unit branch represents one mutation.

\section{Supplementary Files}

This is a list of supplementary files associated with this preprint. Click to download.

- Graphicabstract.tif

- SupplymentTables.docx 